\title{
THE EFFECT OF COLD DRAWING ON PROPERTIES AND MICROSTRUCTURE OF MANGANESE AUSTENITIC STEEL WIRE
}

\author{
${ }^{1}$ Agnieszka TOMASZEWSKA, ${ }^{2}$ Magdalena JABŁOŃSKA, ${ }^{3}$ Marek TKOCZ, ${ }^{4}$ Iwona BEDNARCZYK \\ ${ }^{1}$ The Silesian University of Technology, Gliwice, Poland, EU, \\ 1agnieszka.tomaszewska@polsl.pl, ${ }^{2}$ magdalena.jablonska@polsl.pl, ${ }^{3}$ marek.tkocz@.polsl.pl, \\ ${ }^{4}$ iwona.bednarczyk@polsl.pl
}

https://doi.org/10.37904/metal.2019.828

\begin{abstract}
Thanks to their specific features (such as corrosion resistance, resistance to high temperatures, good mechanical properties, unique physicochemical and aesthetic properties) stainless steels are practically applied in many areas, including construction and architecture, energy production, household appliances, automotive, food, chemical and pharmaceutical industries. Stainless steel products are usually manufactured from three basic steel grades: $301,304,314$ or $316 \mathrm{~L}$, which are high in nickel content. The increase in the price of this raw material has led the stainless steel manufacturers to look for alternative steel grades whose use allows for a significant reduction in production costs while maintaining the same material properties. The aim of this study was to analyze the effect of cold drawing on the structure and properties of 204Cu steel. The tested grade belongs to the cost-effective group of stainless steels, and it can be used as a cheaper alternative to products with similar mechanical properties, while maintaining high corrosion resistance.
\end{abstract}

Keywords: Wire drawing, manganese steel, 204Cu steel

\section{INTRODUCTION}

The cost-effective stainless steels have been developed in order to replace or significantly reduce amount of relatively expensive nickel by means of $\mathrm{Mn}, \mathrm{Cr}$, Si, $\mathrm{Mo}$ or $\mathrm{V}$ additions. The $204 \mathrm{Cu}$ steel is an interesting representative of this material group. It contains manganese, copper and nitrogen and just moderate amount of nickel. Manganese stabilizes austenite and improves weldability. Nitrogen increases strength and pitting resistance while copper improves corrosion resistance and cold formability. Therefore, the 204Cu steel can successfully replace the nickel-rich steels in many applications. Due to relatively low austenite stability at room temperature, a significant fraction of strain-induced martensite forms during cold forming [1], causing increase in strength but also reduction in ductility. Currently selected grades of corrosion-resistant steels, including steel $2014 \mathrm{Cu}$, are used in the form of wires with diameters from 3.5 to $1.5 \mathrm{~mm}$, among others in the food industry. They are a cheaper alternative to high-alloy species and their production in connection with the development of the household appliances industry is constantly growing. With this type of wire diameters, it is important to choose the correct parameters of the drawing process [2,3]. this is important for controlling the transformation of austenite into martensite. Then, in the process of drawing, the strengthening of the material is a component

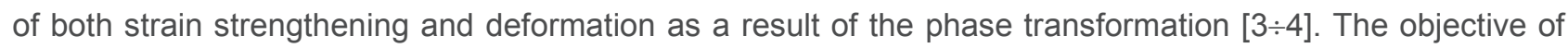
this study was to examine how $204 \mathrm{Cu}$ steel reacts on cold drawing conditions with attention to the effect of strengthening the material both as a result of the mechanism of strain strengthening and deformation as a result of phase transformation.

\section{EXPERIMENTAL PROCEDURE}

The 204Cu steel wire rod ( 3 meters long and $5.65 \mathrm{~mm}$ in diameter) was used as the initial material. The chemical composition is given in Table 1. Prior to cold-drawing, the wire rod was subjected to annealing and subsequent chemical scale removing. 
Table 1 The chemical composition of the investigated 204Cu steel

\begin{tabular}{|c|c|c|c|c|c|c|c|c|c|c|c|}
\hline Element & $\mathbf{C}$ & $\mathbf{C r}$ & $\mathbf{M n}$ & $\mathbf{C u}$ & $\mathbf{N i}$ & $\mathbf{S i}$ & $\mathbf{N}$ & $\mathbf{M o}$ & $\mathbf{P}$ & $\mathbf{S}$ & $\mathbf{F e}$ \\
\hline $\begin{array}{c}\text { Content } \\
\text { (wt\%) }\end{array}$ & 0.043 & 15.746 & 8.200 & 2.078 & 2.061 & 0.487 & 0.147 & 0.080 & 0.030 & 0.005 & balance \\
\hline
\end{tabular}

Cold drawing was performed on a laboratory draw bench (Figure 1). Drawing dies made of cemented carbide and with die angle $2 \alpha$ of $14^{\circ}$ were applied. A mixture of dry lubricants was used to decrease friction. The wire diameter was successively reduced, according to a pass schedule presented in Table 2.
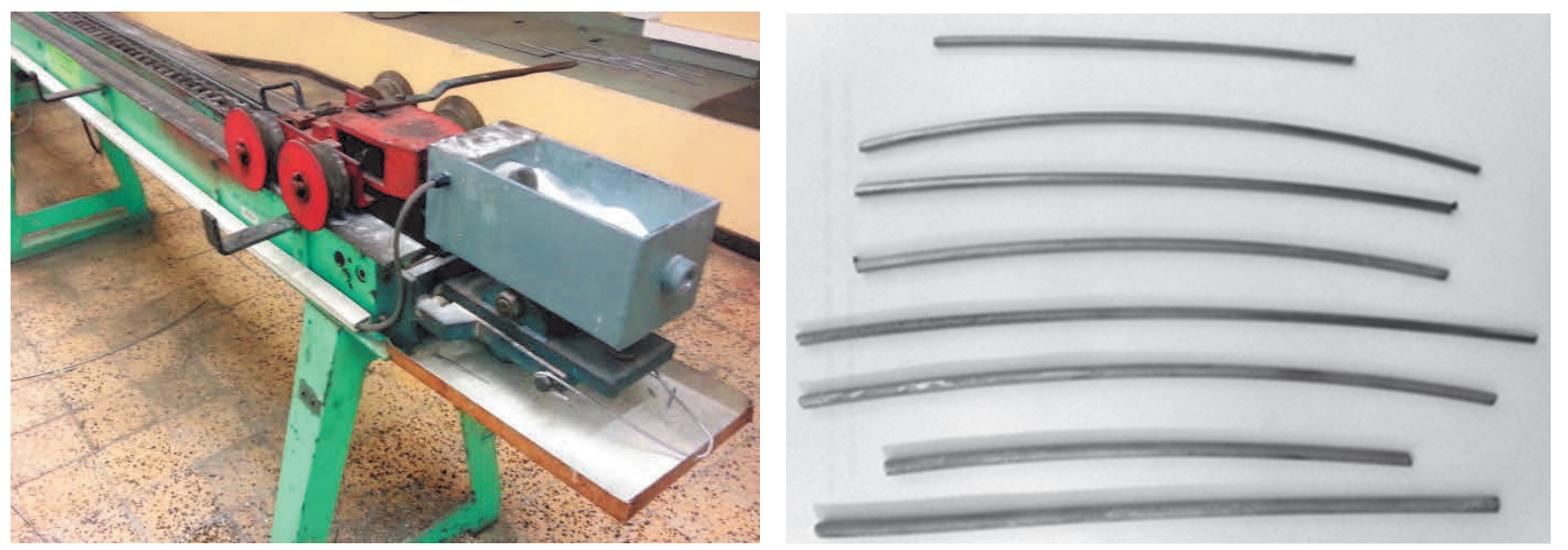

Figure 1 The draw bench used in experiments and selected cold-drawn samples

Table 2 The drawing pass schedule applied

\begin{tabular}{|c|c|c|c|c|c|c|c|}
\hline \multirow{2}{*}{$\begin{array}{c}\text { Pass } \\
\text { No. }\end{array}$} & \multirow{2}{*}{$\begin{array}{c}\text { Wire } \\
\text { diameter } \\
(\mathbf{m m})\end{array}$} & \multicolumn{2}{|c|}{ Reduction in area (\%) } & \multicolumn{2}{|c|}{ True strain } & \multicolumn{2}{c|}{ Elongation ratio } \\
\cline { 3 - 8 } & in a pass & total & in a pass & total & in a pass & total \\
\hline 0 & 5.65 & - & - & - & - & - & - \\
\hline 1 & 5.50 & 5.24 & 5.24 & 0.05 & 0.05 & 1.06 & 1.06 \\
\hline 2 & 5.00 & 17.36 & 21.69 & 0.19 & 0.24 & 1.21 & 1.28 \\
\hline 3 & 4.65 & 13.51 & 32.27 & 0.15 & 0.39 & 1.16 & 1.48 \\
\hline 4 & 4.40 & 10.46 & 39.35 & 0.11 & 0.50 & 1.12 & 1.65 \\
\hline 5 & 4.12 & 12.32 & 46.83 & 0.13 & 0.63 & 1.14 & 1.88 \\
\hline 6 & 3.98 & 6.68 & 50.38 & 0.07 & 0.70 & 1.07 & 2.02 \\
\hline 7 & 3.76 & 10.75 & 55.71 & 0.11 & 0.81 & 1.12 & 2.26 \\
\hline 8 & 3.48 & 14.34 & 62.06 & 0.15 & 0.96 & 1.17 & 2.64 \\
\hline 9 & 3.22 & 14.38 & 67.52 & 0.16 & 1.12 & 1.17 & 3.08 \\
\hline 10 & 3.00 & 13.20 & 71.81 & 0.14 & 1.27 & 1.15 & 3.55 \\
\hline 11 & 2.78 & 14.13 & 75.79 & 0.15 & 1.42 & 1.16 & 4.13 \\
\hline 12 & 2.33 & 29.75 & 82.99 & 0.35 & 1.77 & 1.42 & 5.88 \\
\hline 13 & 2.11 & 17.99 & 86.05 & 0.20 & 1.97 & 1.22 & 7.17 \\
\hline
\end{tabular}

After selected passes samples were prepared for microstructural investigations and mechanical tests. A Nikon Eclipse MA 200 optical microscope were used for microstructure analysis. XRD analysis was performed on a JEOL JDX-7S X-ray diffractometer. Microhardness measurements were conducted by means of a Zwick tester. Static tensile tests were performed at room temperature by means of a Zwick tensile testing machine. 


\section{RESULTS AND DISCUSSION}

\subsection{Metallographic results}

Initial microstructure is presented in Figure 2. In the as-annealed state the investigated steel exhibit a singlephase austenitic microstructure with annealing twins and without any deformation effects.
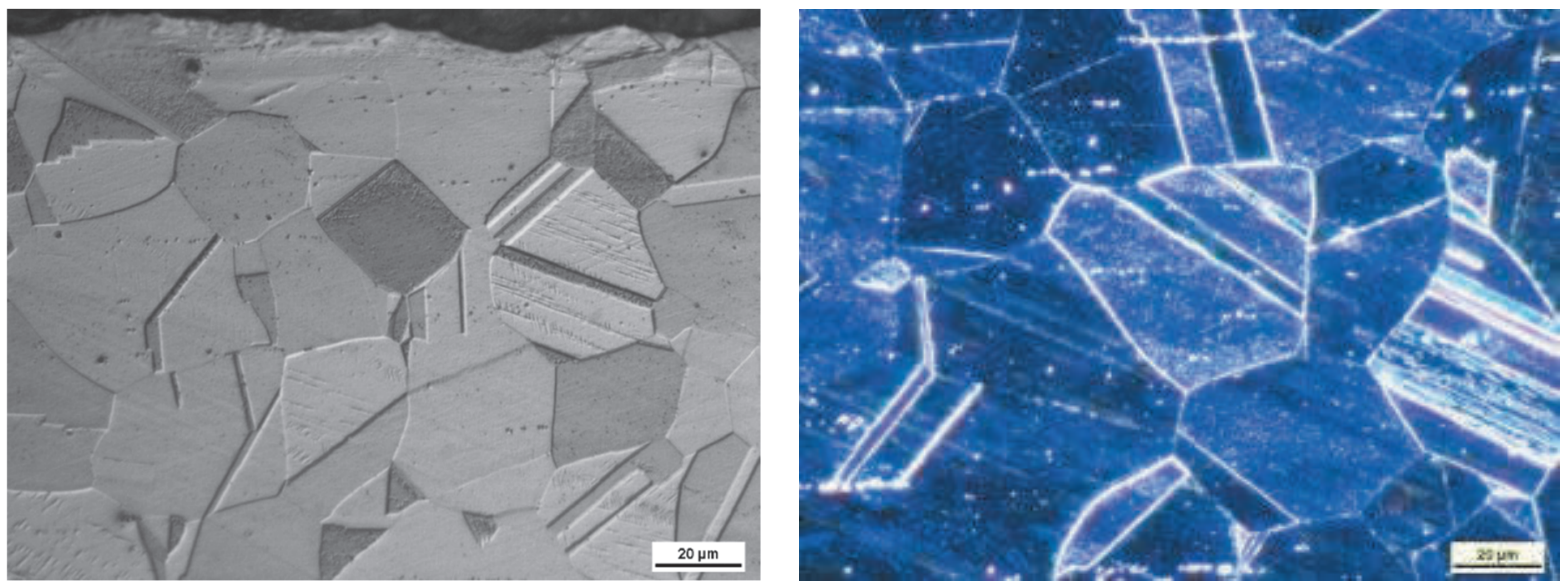

Figure 2 Microstructure of the investigated 204Cu steel in the initial, as-annealed state (DIC and polarized light micrographs)
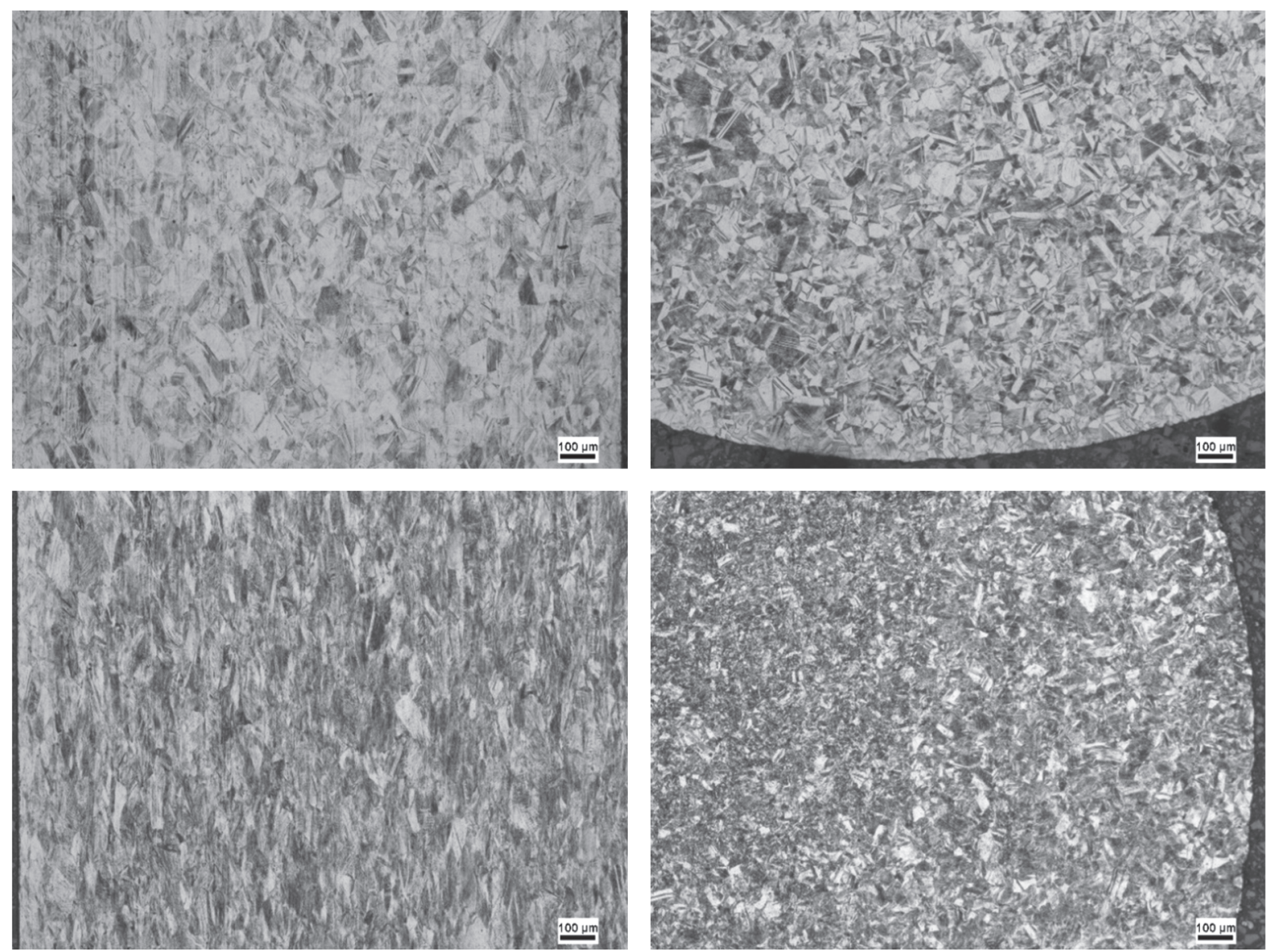

Figure 3/1 Microstructure evolution in 204Cu steel wires subjected to cold drawing: longitudinal sections (left) and cross sections (right): after reduction in area of $22 \%$ (upper row), $50 \%$ (middle row), $72 \%$

(lower row) 

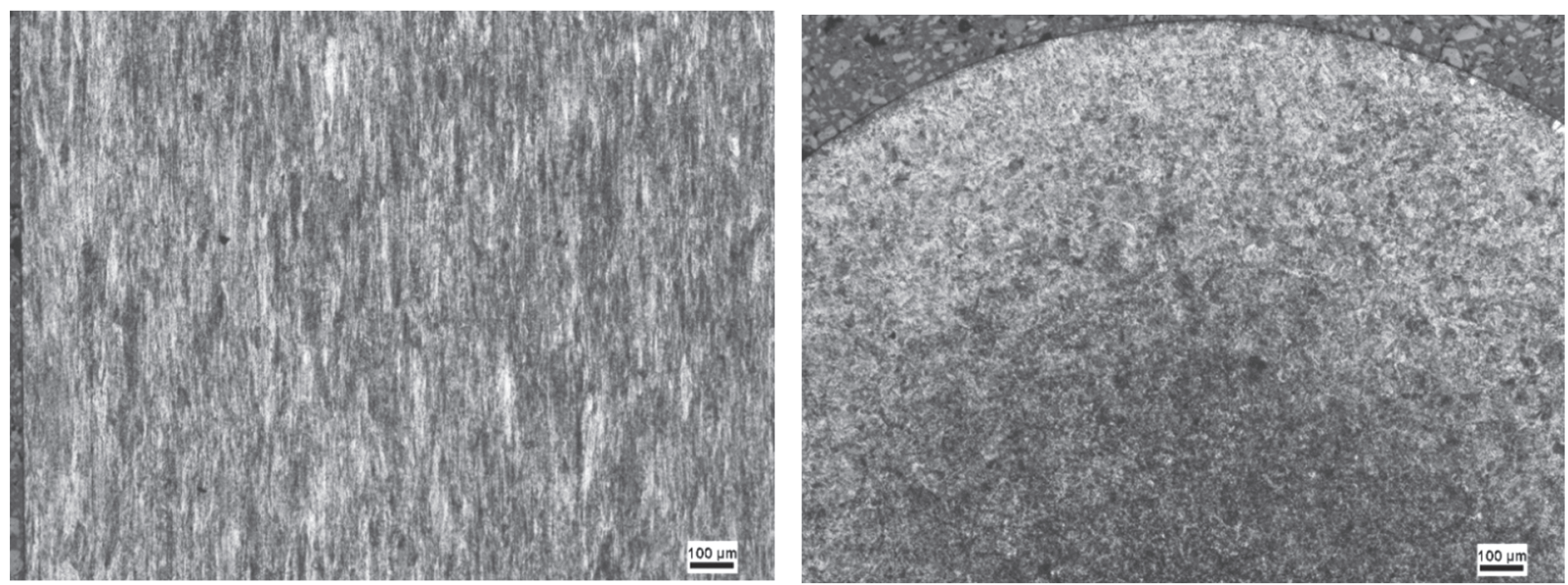

Figure 3/2 Microstructure evolution in 204Cu steel wires subjected to cold drawing: longitudinal sections (left) and cross sections (right): after reduction in area of $22 \%$ (upper row), 50 \% (middle row), $72 \%$

(lower row)

Microstructure evolution during cold drawing are presented in Figure 3. Consecutive grain refinement, microstructure texturing and appearing of deformation twins and slip bands as well as progression of straininduced austenite-martensite transformation was observed. The latter process has been confirmed in XRD examinations (Figure 4).

Finer grains are observed in areas near the surface while coarser ones can be seen near the wire centre. This kind of anisotropy is concerned with the fact that the highest stresses occur just near the working surfaces of a drawing die and so the greatest grain refinement occurs in these areas. In consequence of consecutive drawing passes, grains elongate in the direction of drawing force.
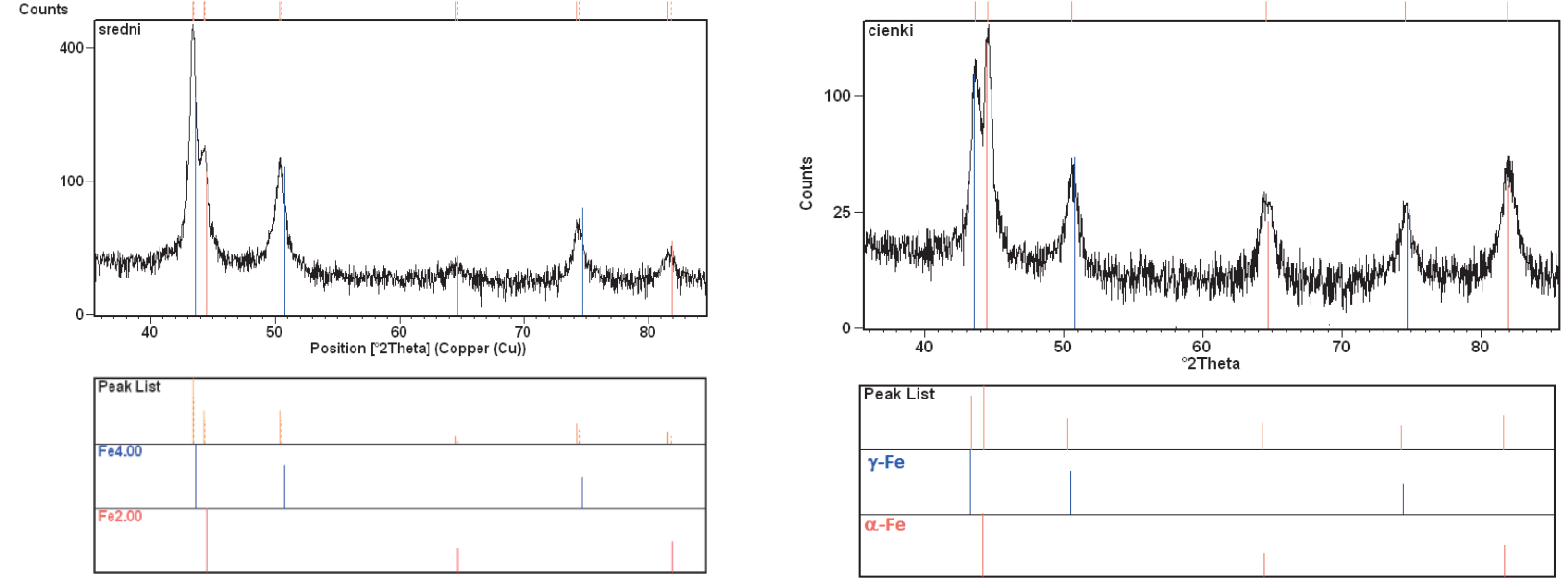

Figure 4 Diffraction patterns obtained for 204Cu steel wires after reduction in area of $50 \%$ and $76 \%$

\subsection{Microhardness and tensile strength}

The results of hardness measurements are shown collectively in Figure 5. The average hardness values were determined on the basis of six measurements by Vickers' method (HV1) taken near the surface or along the centerline of a sample. As expected, a constant increase of the wire hardness is observed after subsequent passes, both due to deformation strengthening and strain-induced martensite transformation. Slightly higher hardness values were obtained near the wire surface, probably due to higher strain values and thereby higher 
deformation strengthening in these areas [4]. Finally, wire hardness increased 3 and a half times (from 200 to $700 \mathrm{HV} 1$ ) after cold drawing conducted according to the selected pass schedule with rather small and moderate single reductions applied.

The results of static tensile tests are presented in Figure 6. The ultimate tensile strength of a 204Cu wire rises after subsequent drawing passes in similar manner as hardness. A sudden drop of the UTS obtained for the samples after the last pass is a result of reaching the wire formability limit in the selected process conditions. The highest UTS value $1900 \mathrm{MPa}$ were obtained for samples after $76 \%$ reduction in area. It is almost 3 times higher value than the UTS of initial, as-annealed material.

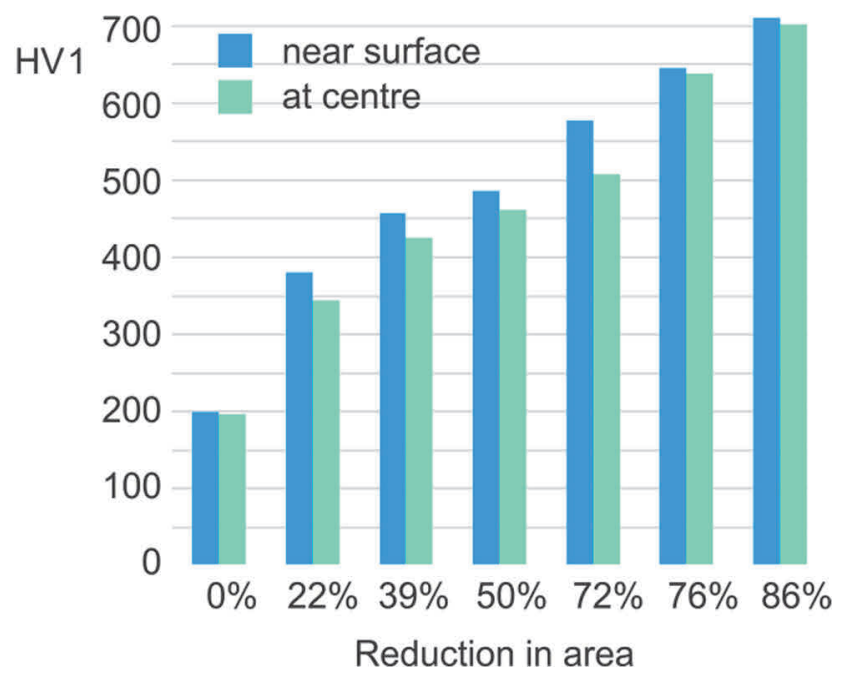

Figure 5 Hardness of 204Cu wire after selected drawing passes

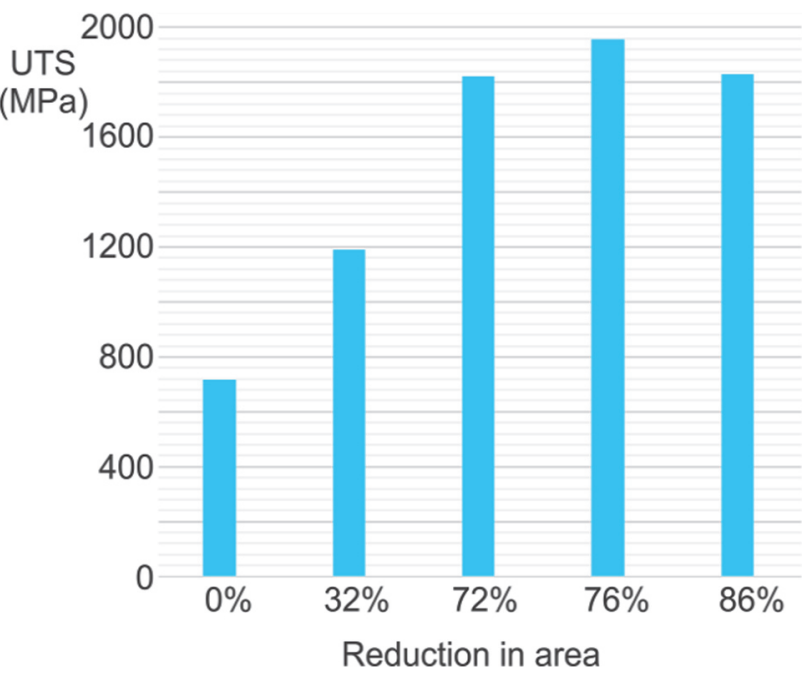

Figure 6 Ultimate tensile strength of 204Cu wire after selected drawing passes

\section{CONCLUSION}

- In the initial (as-annealed) state, the wire rod made of the investigated 204Cu steel exhibits austenitic microstructure.

- During consecutive drawing passes, polygonal austenite grains are subjected to deformation and elongate in the drawing force direction. Cold drawing induces local phase transformations of austenite into deformation martensite.

- The significant increase of hardness and ultimate tensile strength is a result both cold deformation strengthening as well as martensite transformation. Despite this, the significant cold reduction (over $80 \%$ ) without intermediate annealing was obtained as well.

- More detailed, quantitative analysis is planned in the near future in order to assess the effect of cold drawing conditions on grain refinement and progress of martensite transformation in the investigated steel.

\section{ACKNOWLEDGEMENTS}

The work supported by the Ministry of Science and Higher Education within the framework of the project BK-221/RM0/2018 


\section{REFERENCES}

[1] NARAGHI, Reza, BORGENSTAM, Annika and HEDSTÖRM, Peter. Martensitic Transformation in Austenitic Stainless Steels. 2008. [viewed 2019-05-24]. Masters Degree Project. Available from https://www.researchgate.net/publication/268410203

[2] SULIGA, M. The theoretical and experimental analyses of the influence of single draft on properties of rope wires. Archives of Metallurgy and Materials. 2012, vol.57, pp. 1021-1030.

[3] WIEWIÓROWSKA S., MUSKALSKI Z, CIEPIELA W., Intensification of the transition of retained austenite to martensite effected by changing the stress state in TRIP steel wires, Archives of Metallurgy and Materials. 2015, vol.60 pp. 2729-2732.

[4] TOMASZEWSKA A, JABŁOŃSKA, M., HADASIK, E., NIEWIELSKI, G., KAWALLA, R., Research of selected properties of two types of high manganese steel wires, IOP Conference Series: Materials Science and Engineering; vol. 22, 1. 1757-8981. doi:10.1088/1757-899X/22/1/012015 